\title{
Future scenarios for oil palm mortality and infection by Phytophthora palmivora in Colombia, Ecuador and Brazil, extrapolated to Malaysia and Indonesia
}

\author{
R. Russell M. Paterson
}

Received: 20 August 2019/Accepted: 19 May 2020 /Published online: 27 May 2020

(C) Springer Nature B.V. 2020

\begin{abstract}
Palm oil is a very important commodity especially to Malaysia and Indonesia. However, Latin American countries have significant industries, particularly Colombia. Climate change (CC) is a highly probable phenomenon which will affect diseases of oil palm (OP) with Phytophthora palmivora causing devastating outbreaks in Latin America and especially Colombia. Furthermore, the oomycete is an endemic pathogen to other crops in Malaysia such as durian, and is capable of causing disease of OP in vitro. A similar disease has been recorded in Thailand. It is crucial that $P$. palmivora is controlled in Malaysia and Indonesia because the organism is highly virulent, although there are acute and chronic forms. This current paper investigates the effect of CC on P. palmivora disease and on OP survival via a CLIMEX model for future suitable growth of OP. Postulated schemes are provided for Malaysia and Indonesia for acute and chronic forms of the disease which indicate an extremely high and increasing threat, likely to reduce the sustainability of the OP industry by 2050 and further by 2070 and/or 2100. Brazil appears less threatened by the disease under these scenarios, but their OP is likely to have $100 \%$ mortality. The chronic and acute forms of the malady present reduced and high
\end{abstract}

\footnotetext{
R. R. M. Paterson ( $\bowtie)$

CEB-Centre for Biological Engineering, University of Minho,

4710-057 Braga, Portugal

e-mail: russell.paterson@deb.uminho.pt
}

\section{R. R. M. Paterson}

Department of Plant Protection, Faculty of Agriculture, Universiti Putra Malaysia, 43400 UPM Serdang, Selangor, Malaysia threats respectively to Malaysia and Indonesia. The data herein will be useful for, inter alia, plantation managers who will be able to assess the accuracy of these scenarios in the future. Amelioration methods are required urgently and quarantine procedures need strengthening.

Keywords Lethal bud rot · Elaeis guineensis . CLIMEX · Agriculture 4.0

\section{Introduction}

The importance of palm oil to the economies of Indonesia and Malaysia is high and there are thriving palm oil industries in Latin America and Africa (Paterson et al. 2017). The oil is included in swathes of foods, cosmetics, pharmaceuticals, biodiesel and is employed in domestic cooking. Expansion of oil palm (OP) plantations has well-known detrimental environmental consequences (Paterson and Lima 2018) and the oil has been associated with considerable human health problems (Kadandale and Smith 2019) adding to its significance.

Palm oil manufacturing began commercially in Malaysia in 1917 (Basiron 2007) and 85\% of palm oil is now produced by Malaysia and Indonesia (Ommelna et al. 2012), which export very high quantities. Low costs, high efficiency, large production potential and straight forward planting make the crop highly remunerative (Dislich et al. 2017). OP cultivation produces 3-8 times more oil than any other oil crops per hectare and is a huge global industry (Barcelos et al. 2015), 
worth over USD 50 billion annually (Murphy 2014). Cultivation of ca. 15 million ha throughout the world have been reported and expansion of $43 \%$ in area is predicted (Koh and Wilcove 2008), although the effect of climate change (CC) on OP was not considered in Koh and Wilcove (2008).

Awareness of the effects of CC on crop production and disease has increased (Lobell et al. 2006), although the effects on tropical crops are less well known (Ghini et al. 2011). Climate change threatens the sustainability of crop production. Experiments, analogies and models were used when estimating future climate-related risks, vulnerabilities and impacts in the 2014 Intergovernmental Panel on Climate Change (IPCC) report (IPCC 2014). Models can be predominantly descriptive narratives of possible futures, such as those used in scenario construction. Also, they can be numerical simulations of real-world systems, calibrated and validated from experiments or analogies, and then run using data representing future climate. The quantitative and descriptive models are often used together in a complementary manner. Impacts are modelled, inter alia, for ecosystem services and agricultural productivity including diseases of crops.

The highly detrimental impact and significance of $\mathrm{CC}$ is confirmed extensively in the scientific community and increasingly acknowledge by the general public, as is well known. All living species and ecosystems on which they depend are threatened and there is a great deal of evidence on the impact on global species distributions. Paterson et al. (2017) determined the detrimental affect on the suitability of future climate on OP growth in a global setting. Ramirezcabral et al. (2017) indicated that large areas that are suitable for global maize cultivation will suffer from heat and dry stresses that may constrain production. Shabani et al. (2014) determined the future distribution of plant pathogenic Fusarium oxysporum and indicated that the climate would become more suitable for the fungus in the future in some countries, threatening more infection of crops. However, there are few modelling projections of OP disease apart from (Paterson 2019a), (Paterson 2019b) and (Sarkar 2020).

The effects of CC are manifested by phenology (Thackeray et al. 2010), who suggested that future climate warming may further disrupting the functioning, persistence and resilience of many ecosystems and have a major impact on ecosystem services. Their observations were extrapolated, employing expert opinion, to a future based on current observations. Walsh et al. (2016) reported morphological changes in the chipmunk related to $\mathrm{CC}$ and concluded that anthropogenic CC was having a significant impact on physical and biological systems globally. Rosenzweig et al. (2008) discussed demographic changes from CC. Bellard et al. (2012) pointed out the weaknesses of models in that all relevant parameters cannot be considered, but also indicated that demographics can change and that climate scenarios depend on a wide range of socio-economic "storylines" for anticipated greenhouse gas emissions in the future. Studies indicate high levels of ecological changes by the use of scientific inference (Parmesan 2006). Extinction rates (Sinervo et al. 2010) will accelerate with the intensification of $\mathrm{CC}$, which was confirmed in a meta-analysis undertaken by Urban (2015), who analysed numerous studies on extinction and $\mathrm{CC}$, which included computer modelling and expert opinion. The majority of studies extrapolate correlations between current climate and species distributions to novel conditions and omit important biological mechanisms, including species interactions, evolution, landscape dispersal barriers, habitat degradation, and intraspecific trait variation. Conservation scientists, managers and environmental policy makers need to adapt their guidelines and policies accordingly (Brooke 2008) to mitigate the impact of CC. Procedures for amelioration have been discussed for OP (Paterson and Lima 2018) which was partially based on CLIMEX models in Paterson et al. $(2015,2017)$.

Furthermore, large scale conversion of tropical forest to OP plantations has detrimental effects on biodiversity. Fitzherbert et al. (2008) determined that OP plantations support many fewer species than forests and some other tree crops. Habitat fragmentation and increased pollution occur, including greenhouse gas emissions. OP cultivation affects climate by increasing greenhouse gas emission and consequently CC (Paterson and Lima 2018). Koh and Wilcove (2008) suggested that OP expansion occurred at the expense of forests which may result in biodiversity loss. Dislich et al. (2017) determined 11 of 14 ecosystem functions decreased in levels of function by the introduction of OP plantations.

Diseases of OP will be subjected to the effects of CC and a general increase in disease was considered likely using an expert-opinion approach (Paterson et al. 2013). Also, a large decrease in suitable climate for growing OP has been argued using CLIMEX modelling (Paterson et al. 2015, 2017). The general decrease in 
suitability for growing OP may result in higher disease, as determined for basal stem rot (BSR) of OP (Paterson 2019a, b, 2020b) which combine CLIMEX and narrative modelling.

The fungus-like oomycete, Phytophthora palmivora, is a notorious pathogen of OP which has caused severe damage in Latin American countries, with Colombia being affected severely (Corley and Tinker 2015). The first plantations in Colombia were, of course, free of the disease. The disease has destroyed several Colombian plantations since 1964 and has recently decimated more than (a) 30,000 ha in the South West Colombia and (b) 10,000 ha in the Central Zone. As a general hypothesis, this rapid increase in the disease may be related to $\mathrm{CC}$ (Paterson et al. 2013), which is considered further in the present paper. The infection is endemic at all stages from nursery to the end of the production cycle. $P$. palmivora involved in lethal bud rot is also referred to as fatal yellowing (FY) and it is associated with a bud rot of variable symptoms depending on location, but does not "usually" have the little leaf symptom of spear rot. P. palmivora was isolated from diseased palms in central and south western regions of Colombia and the organism was proven involved in some cases (Corley and Tinker 2015). However, Yonara et al. (2018) implied that $P$. palmivora is not involved in the disease of FY in Brazil, but their methods to identify the oomycete were discredited by (Paterson 2020a) and their results do not support the contention that $P$. palmivora is not involved in FY.

Some plantations suffered serious losses with palms remaining unproductive for long periods, whereas others experienced complete devastation. Acute and chronic forms are apparent and it may be that various diseases have been described under one name. The acute forms are present in Colombia and Ecuador and the chromic form appears the cause in Brazil.

Importantly, the symptoms are affected by climate and so CC will also affect the disease: For example, high humidity is conclusive in the spread of the disease (Corley and Tinker 2015).

The fungal pathogen, Ganoderma boninense causes BSR with the ability to infect OP at a rate of as much as $80 \%$ incidence at $50 \%$ of the economic life span of ca. 20 years (Corley and Tinker 2015). Paterson (2019a) provided a scenario of $3 \%$ increase in the disease every 10 years simply from increased virulence of the fungus from CC. However, the acute form of the P. palmivora disease spreads much faster and the disease occurs in weeks or months after the infection appears and consequently is potentially more serious than $G$. boninense. In the space of a few years, devastating, acute outbreaks of $P$. palmivora were experienced which may have been related to $\mathrm{CC}$ and a chronic, ongoing level of the disease was also experienced (Corley and Tinker 2015). The treatment of the ailment appears to involve culling OP surrounding the infected areas, which becomes untenable if the disease takes hold because of CC.

Nevertheless, $P$. palmivora disease of OP is unreported in Malaysia and/or Indonesia despite being the major growers. A spear rot of OP has been reported in Africa and Thailand which may involve $P$. palmivora (Corley and Tinker 2015) which may be a different form of the disease. Indeed, the maladies of spear rot and lethal bud rot are similar. Many other hosts for the oomycete are grown or exist in Malaysia and Indonesia (e.g. durian) and P. palmivora presents a severe threat to Malaysian and Indonesian plantations, particularly after an extreme outbreak in Colombia was reported (Sundram and Intan-Nur 2017). Mohamed Azni et al. (2017) tested strains of $P$. palmivora isolated from alternative Malaysian crops for infection of OP and demonstrated that Malaysian OP materials were susceptible to infection from local strains. The authors speculated that Colombian P. palmivora may have undergone sequential genetic shift to become more virulent towards Colombian OP planting materials, also indicating the potential adaptability of the oomycete, possibly in relation to CC. The observation that Malaysian $P$. palmivora could cause problems for the Malaysian OP industry indicates more assessments of infectivity are essential.

The mapping of potential pest distributions plays a role in biosecurity planning, specifying areas that qualify for eradication, or those where containment of the threat may be the more cost-effective option. The mechanistic CLIMEX model was developed for modeling current and future species distribution. Enhancing the capacity to model the effects of $\mathrm{CC}$ on species distributions is essential in mitigating its negative impact. da Silva et al. (2018) sensitivity analysis demostrated eleven and ten parameters were particularly significant in assessing species distribtioin for Solanum lycopersicum and Neoleucinodes elegantalis respectively. Lamsal et al. (2017) reported that high elevation belts in the Himalayas and Tibetan Plateau will see more climatically suitable areas for nine native plant species in the future. Ramirez-cabral et al. 
(2017) demonstrated heat stress as particularly significant on maize in determining distribution. Shabani et al. (2016) who employed an integrated assessment, indicated that cold and heat stress are the most crucial factors limiting the distribution of date palm in Iran.

Climate change could increase, decrease or have no effect on OP diseases (Paterson et al. 2013; Paterson and Lima 2018): an increase causes concern and requires action to ameliorate the effect. The extent to which BSR scenarios provided in Paterson (2019a, b, 2020b) are accurate will emerge with time (see Results and discussion). In the current paper, scenarios were devised from climate suitability maps to assess (a) the effect of $\mathrm{CC}$ on the survival of OP and (b) the progress of $P$. palmivora disease of $\mathrm{OP}$ based on three countries in Latin America and extrapolated to Malaysia and Indonesia. This is a unique approach to assessing the significance of $P$. palmivora disease of OP.

\section{Materials and methods}

Suitable climate for growing oil palm

The models described in Paterson et al. (2015) and Paterson et al. (2017) provided scenarios of suitable climate for growing OP under CC. Paterson et al. (2017) was used to provide information from the maps for Colombia, Ecuador, Brazil, Malaysia and Indonesia for current time, 2050 and 2100. Paterson et al. (2015) was used to provide information from maps for Malaysia and Indonesia for current time, 2030, 2070 and 2100. The maps provided in Paterson et al. (2015) and Paterson et al. (2017) were magnified on a computer screen to focus on these regions specifically using the standard magnification facility. The percentages of suitable climates were determined by assessing visually the areas of each designated colour on the maps, where each colour represented a particular degree of climate suitability for growing OP.

The distribution model for OP under current and future climate was developed using CLIMEX for Windows Version 347 (Hearne Scientific Software Pty Ltd, Melbourne 2007) and climate data and CC scenarios were carried out using CliMond 10' gridded climate data. The potential future climate were characterized using A1B and A2 SRES scenarios (Paterson et al. 2015) available as part of the CliMond dataset. The fitting of CLIMEX Parameters employed the Global
Biodiversity Information Facility. Information on the global distribution of OP was used in parameter fitting and 124 records were used. SE Asian distribution data were reserved for validation of the model.

The OP distribution was determined by the Global Biodiversity Information Facility (GBIF) (http://www. gbif.org/, accessed 9 November 2015) and additional literature on the species in CAB Direct (http://www. cabdirect.org/web/about.html, accessed October 2015), and formed the basis for the collection of data on the Elaeis guineensis distribution in (Paterson et al. 2017) with 2465 records utilized in fitting the parameters. CLIMEX in conjunction with the A2 Special Report on Emissions Scenarios (SRES) scenario, a mechanistic niche model using CLIMEX software supports ecological research incorporating the modelling of species' potential distributions under differing climate scenarios and assumes that climate is the paramount determining factor of plant and poikilothermal animal distributions. CLIMEX output categorized areas according to highly suitable climate, suitable climate, marginal climate and unsuitable climate based on other studies through CLIMEX. The determinations of the mortality of OP are determined from especially marginal and unsuitable climate increases.

Oil palm mortality

The suitable climate for growing OP data were used to create schemes for OP mortality by postulating that large degrees of unsuitable and marginal climates in particular were likely to cause high amounts of OP mortality and vice versa. Also, reductions in highly suitable and/or suitable climate per se would not cause a significant effect on OP mortality (Paterson 2020b).

\section{Determination of Phytophthora palmivora}

The models described in Paterson et al. (2015) and Paterson et al. (2017) were further employed to develop schemes of future incidence and severity of disease by $P$. palmivora. The initial levels of the disease were determined from reports in the literature. From first symptoms to death takes 1-3 years for the chronic form of the disease which is similar to BSR in SE Asia (Paterson 2019a, 2020b), where a 3\% increase in disease was postulated every 10 years. However, this value was modified to account for variation in suitable climate between countries. Only the chronic form appears 
present in Brazil. The acute form takes ca. 1 to 4 months from first symptoms to death and only this is present in Colombia and Ecuador (Corley and Tinker 2015). An approximate increase of $20 \%$ every ten years is employed for the acute form of the disease, although this is modified to account for variation in suitable climate between countries. For example, as the percentage of highly suitable climate decreased the incidence rate increased as indicated in the various figures supplied herein. Scenarios of acute and chronic forms of the disease are provided for Malaysia and Indonesia but from a very low level in the current time, as the disease is considered not present in significant quantities these two countries (see Introduction).

\section{Results and discussion}

Colombia had an elevated level of highly suitable climate for growing OP of 70\% in current time with $30 \%$ unsuitable climate (Fig. 1). Highly suitable climate significantly decreased and marginal climate increased greatly to $20 \%$ by 2050 . The scenario for 2100 was of a particularly significant amount of unsuitable climate of $90 \%$. Mortalities of OP particularly from unsuitable climate were $20 \%$ and $90 \%$ in 2050 and 2100 respectively. The framework for $P$. palmivora disease is that the oomycete will have infected $100 \%$ (Fig. 2) of the $80 \%$ surviving OP (Fig. 1) by 2050 . The situation is worse by 2100 with $10 \%$ of OP being alive but they would all be infected with P. palmivora. The OP industry will be unsustainable well before 2050 in Colombia under these scenarios.

The derived scheme for Ecuador was different to Colombia for two suitable climate categories for growing OP (Fig. 3). Highly suitable climate was at a low level of $40 \%$ with a high amount of unsuitable climate of $60 \%$ in current time. This remained the same until 2050 and then the level of unsuitable climate for growing OP increased to $90 \%$ by 2100 . Hence the mortality rate of OP was assessed as zero in 2050 from climate, and increased to $75 \%$ by 2100 by employing this scenario (Fig. 2). The two countries had a similar pattern for the disease although the incidence by 2050 was lower at $80 \%$ (Fig. 2), because the decrease in suitable climate was less severe for Ecuador (Figs. 1 and 3). Eighty $\%$ of the $\mathrm{OP}$ in 2050, none of which had died from inclement climate, were considered infected with $P$. palmivora, implying that palm oil production would be severely compromised by this time. The remaining $25 \%$ of OP in 2100 (Fig. 3) would all be infected (Fig. 2), which would be unsustainable if this postulated framework proves accurate in reality.

The scenarios for Brazil (Fig. 4) are considerably different from Colombia and Ecuador. Highly suitable climate for growing OP was at an intermediate level of $60 \%$ in current time, with $10 \%$ suitable climate. Unsuitable climate was high at $25 \%$. Highly suitable climate decreased considerably by 2050 to $25 \%$ and, significantly, marginal climate increased to $28 \%$ from $5 \%$. By 2100 there was a dramatic increase in unsuitable climate to $81 \%$. Hence the scenario for the mortality of OP was higher than for the previous two countries: There was $15 \%$ dead OP from climate by 2050 rising to $100 \%$ by 2100 (Fig. 4). However, the increase in infection was lower than for Colombia and Ecuador (Fig. 2) because Brazil is considered to have the chronic variety of the disease (see Introduction). The incidence of the disease was assessed to rise to 25 and $100 \%$ by 2050 and 2100 respectively. Hence, $25 \%$ of the $85 \%$ of surviving OP in 2050 will have the disease. Thereafter the disease will be irrelevant because there will be no surviving OP because of the inclement climate (Fig. 4).

The suitable climate for Malaysia (Fig. 5) was not assessed to deteriorate as rapidly the Latin American countries. In fact, highly suitable climate tended to increase until 2050 from an already high level at current time and remained at a high level until 2070. Consequently the amount of dead OP from climate would be zero until 2070 under this scenario. The climate is considered to deteriorate for growing OP after 2070 with a large increase in marginal climate to $31 \%$ by 2100. The mortality rate of OP was $10 \%$ by this time (Fig. 5). The level of $P$. palmivora disease increased at a low rate to $20 \%$ by 2070 when the chronic form of the disease was considered (Fig. 6). The disease scenario for 2100 was $50 \%$ incidence. Hence, in 2100 there would be $90 \%$ living OP, but $50 \%$ of these would have $P$. palmivora. The disease increases to $21 \%$ by 2030 if the acute form of the disease is considered from an initially low level in current time (Fig. 6). This developed to 61,100 and $100 \%$ by 2050, 2070 and 2100 respectively. Hence the disease will have a major impact on the surviving OP. Clearly, although some OP would survive the unsuitable climate, the extremely high incidence of the disease would destroy the plantations.

The situation is remarkably similar for Indonesia (Fig. 7) to Malaysia and the viability of the OP industry 


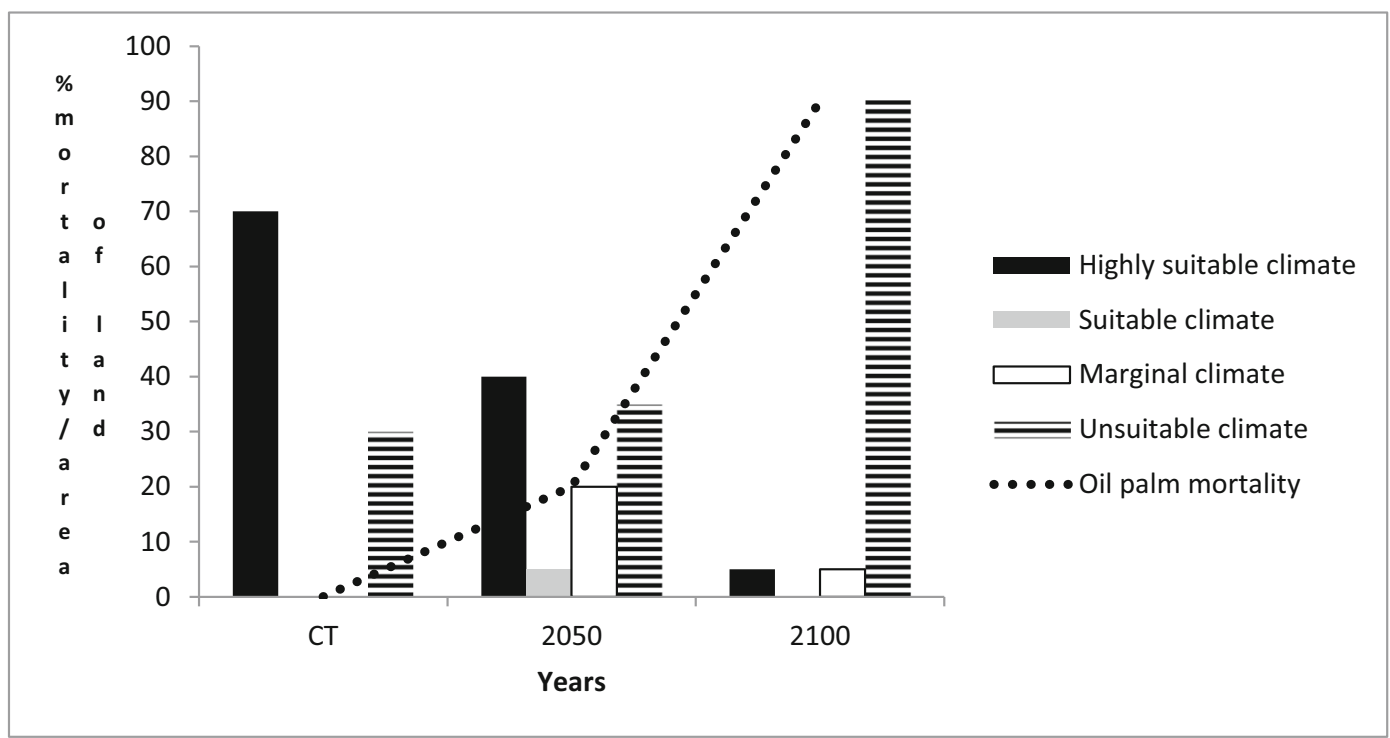

Fig. 1 Change in suitable climate for growing oil palm together with oil palm mortality in Colombia. The percentages represent the areas of land which had highly suitable, suitable, marginal and unsuitable climates and were taken from the maps in Paterson et al. (2017), where each suitability was designated a different colour.

will be threatened in Indonesia also, especially from the acute form of the disease (Fig. 6). There was an elevated, slightly increasing, level of highly suitable climate from current time to 2050. The level of merely suitable climate was high even until 2070 . The mortality rate of
The time scales were current time (CT), 2050 and 2100 (Paterson et al. (2017). The mortality of oil palm was assessed from the change in climate suitabilities particularly emphasizing the influence of marginal and unsuitable climates

OP from climate was assessed to only increase to $10 \%$ by 2100 from 3\% in 2070 (Fig. 7). Forty five \% (Fig. 6) of the remaining $90 \%$ of OP by 2100 (Fig. 7) will be infected if the chronic form is considered. The disease could be manageable in Indonesia if this is what

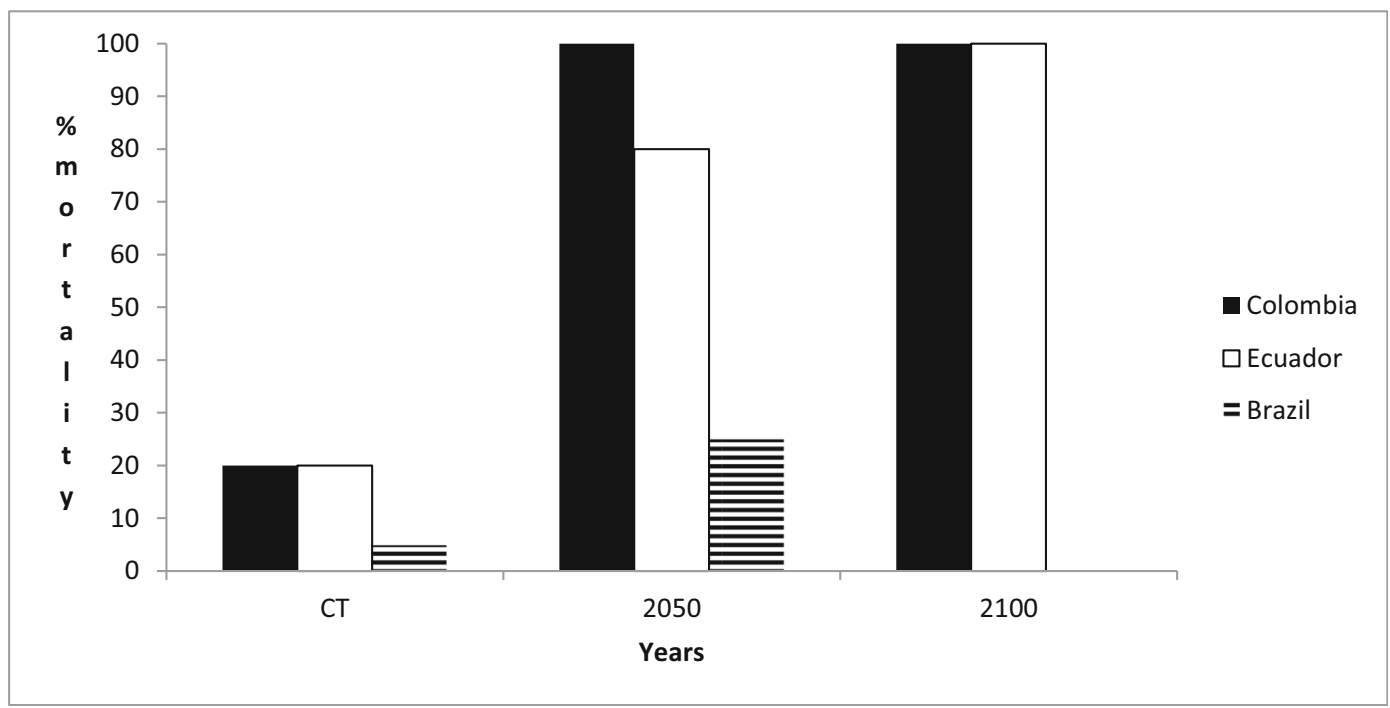

Fig. 2 Infection of oil palm with Phytophthora palmivora in Colombia, Ecuador and Brazil. The incidence of disease was assessed by considering how much $P$. palmivora would increase because of altered climate for oil palm growth at each time period. A scenario of a $3 \%$ increase in BSR every 10 years was employed for Brazil which has the chronic form of the disease. A higher rate of ca. $20 \%$ was employed for Ecuador and Colombia which have the acute for of the disease (see Material and methods for more information) 


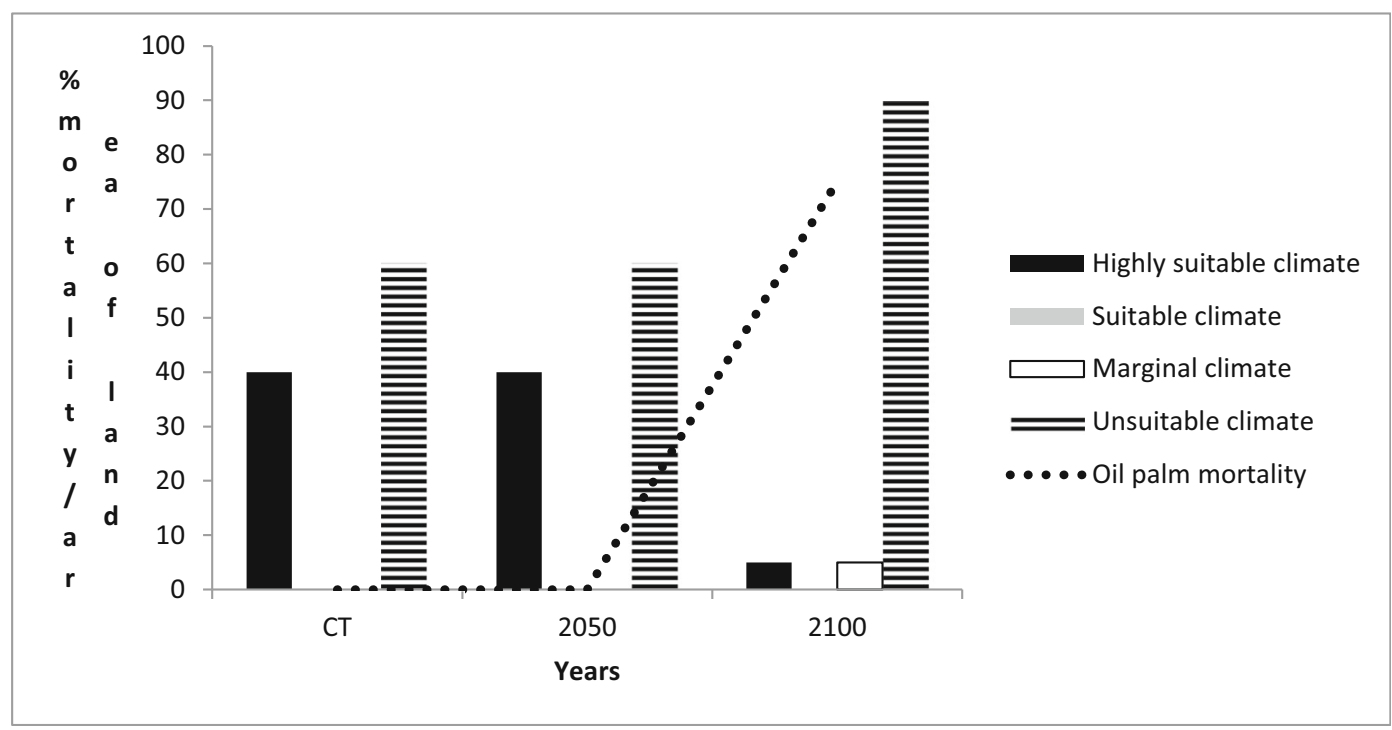

Fig. 3 Change in suitable climate for growing oil palm together with oil palm mortality in Ecuador. The percentages represent the areas of land which had highly suitable, suitable, marginal and unsuitable climates and were taken from the maps in Paterson et al. (2017), where each suitability was designated a different colour.

occurred in the future. However, if the acute form took hold there would be 66, 100 and $100 \%$ incidence by 2050, 2070 and 2100 respectively which would be devastating.
The time scales were current time (CT), 2050 and 2100 from Paterson et al. (2017). The mortality of oil palm was assessed from the change in climate suitabilities particularly emphasizing the influence of marginal and unsuitable climates

The spread of disease will be affected by the level of future climatic stress. The occurrence of dry stress is of particular relevance to the spread of $P$. palmivora, because the disease is enhanced by wet, humid conditions

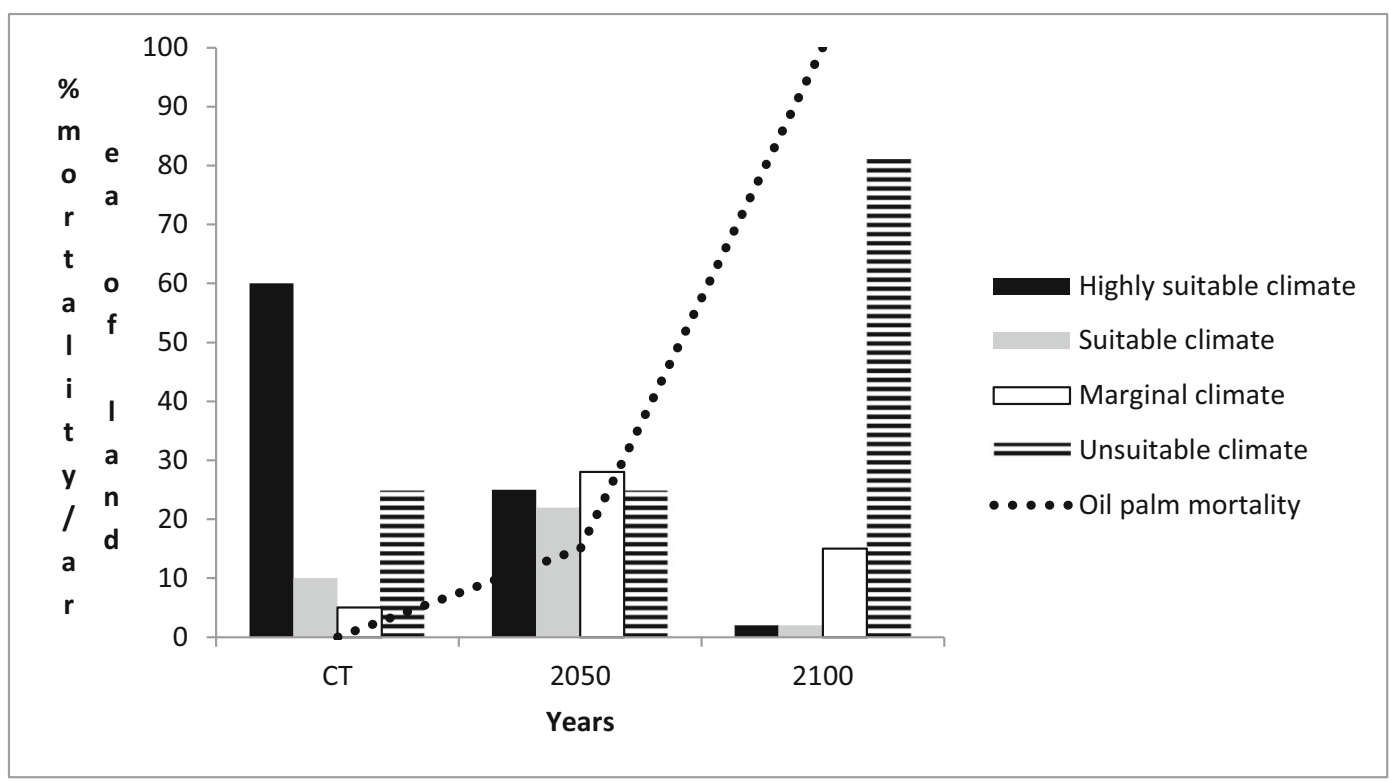

Fig. 4 Change in suitable climate for growing oil palm together with oil palm mortality in Brazil. The percentages represent the areas of land which had highly suitable, suitable, marginal and unsuitable climates and were taken from the maps in Paterson et al. (2017), where each suitability was designated a different colour.
The time scales were current time (CT), 2050 and 2100 from Paterson et al. (2017). The mortality of oil palm was assessed from the change in climate suitabilities particularly emphasizing the influence of marginal and unsuitable climates 


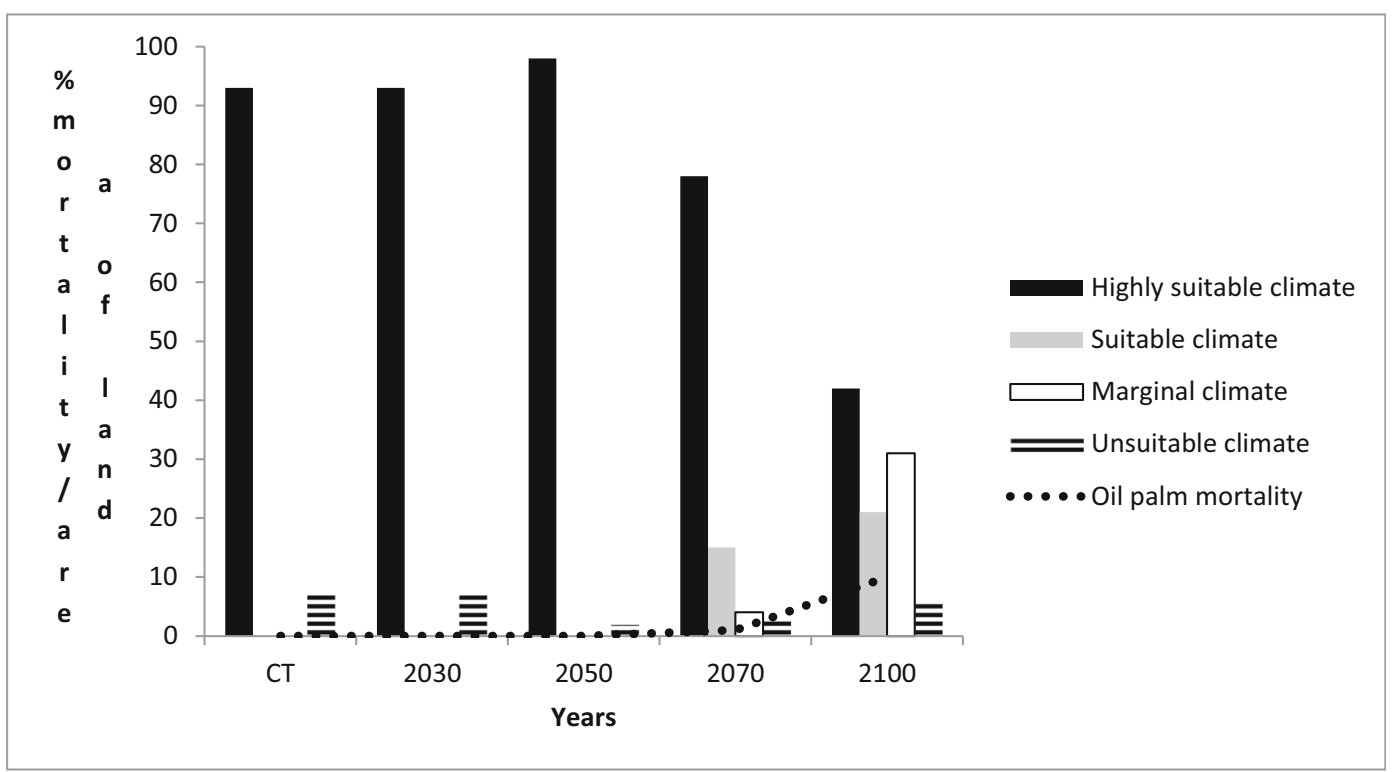

Fig. 5 Change in suitable climate for growing oil palm together with oil palm mortality in Malaysia. The percentages represent the areas of land which had highly suitable, suitable, marginal and unsuitable climates and were taken from the maps in Paterson et al. (2015) and Paterson et al. (2017), where each suitability was designated a different colour. The time scales were current time
(CT), 2030, 2070 and 2100 from Paterson et al. (2015) and CT, 2050 and 2100 from Paterson et al. (2017). The mortality of oil palm was assessed from the change in climate suitabilities particularly emphasizing the influence of marginal and unsuitable climates

in Colombia and Ecuador. Small parts of southern Java, Indonesia and the islands south of Java are assessed to experience dry stress in 2100 (Paterson et al. 2015).

(Corley and Tinker 2015). Dry stress was determined only in a small part of eastern Brazil for the 2050 and 2100 scenarios (Paterson et al. 2017), with no dry stress

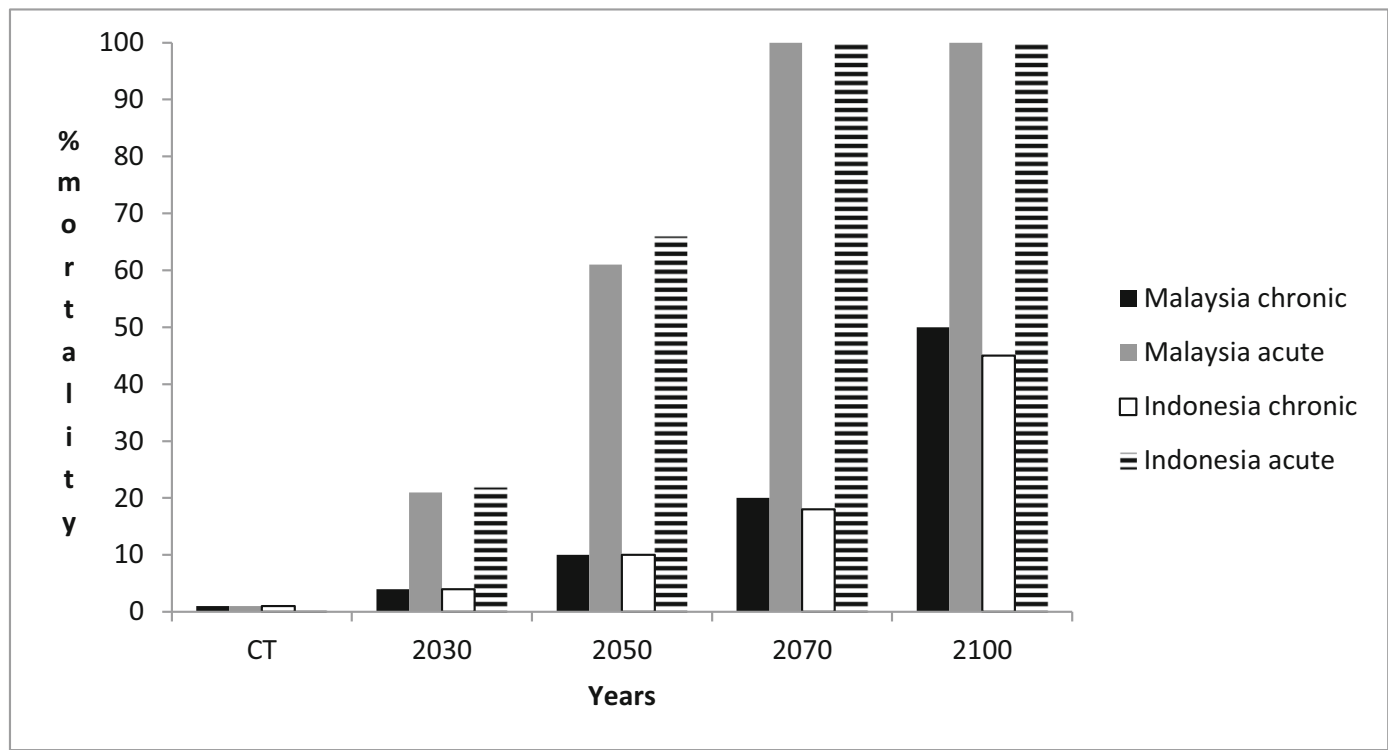

Fig. 6 Infection of oil palm with acute and chronic Phytophthora palmivora for Malaysia and Indonesia. The incidence of disease was assessed by considering how much $P$. palmivora would increase because of altered climate for oil palm growth at each time period. A scenario of ca. $3 \%$ increase in BSR every 10 years was employed for Brazil which has the chronic form of the disease. A higher rate (ca. 20\%) was employed for the acute disease. However, these figures were modified to account for changes in climate suitability (see Material and methods) 


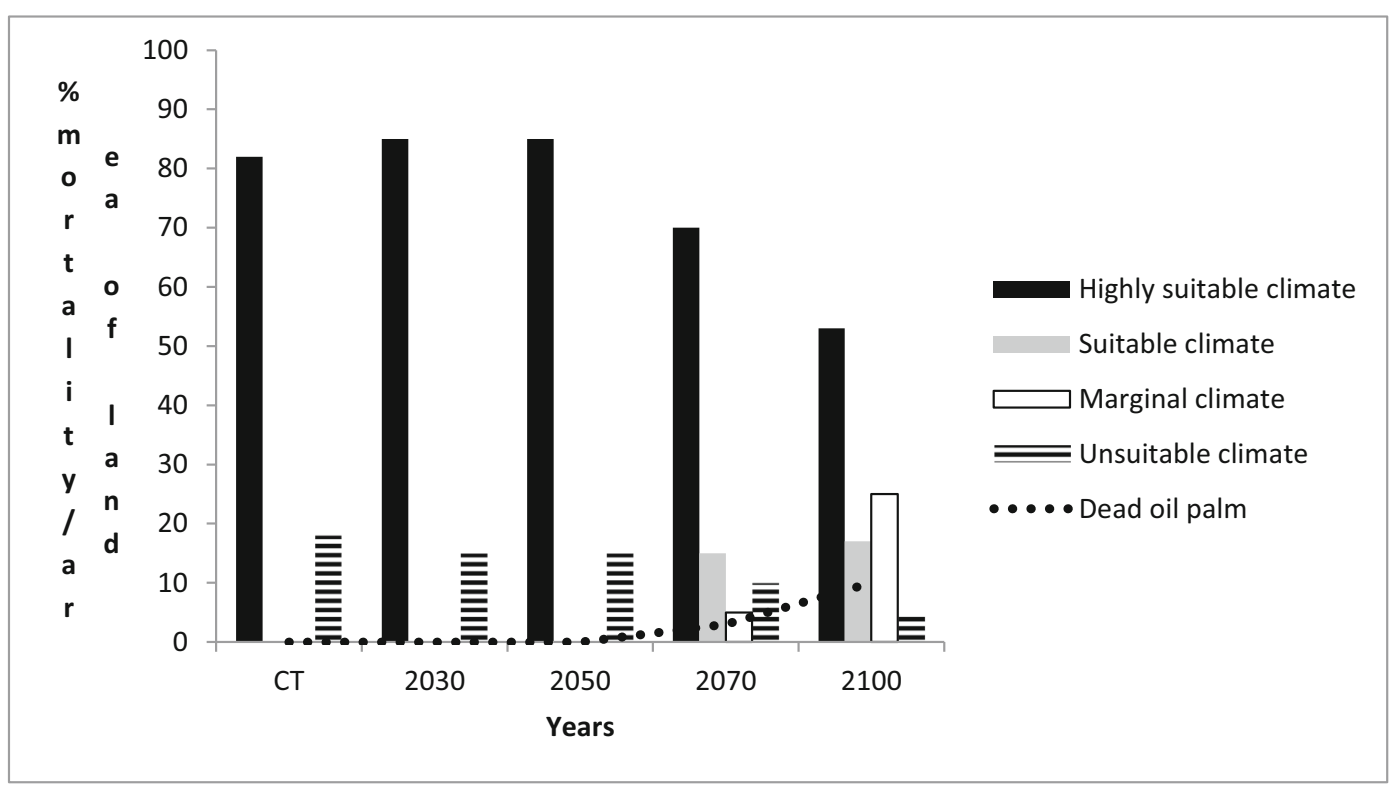

Fig. 7 Change in suitable climate for growing oil palm together with oil palm mortality in Indonesia.. The percentages represent the areas of land which had highly suitable, suitable, marginal and unsuitable climates and were taken from the maps in Paterson et al. (2015) and Paterson et al. (2017), where each suitability was designated a different colour. The time scales were current time

Higher humidity would be maintained in the other parts of these countries thereby enhancing the spread of $P$. palmivora to the other regions considered in the present report.

The threat posed by P. palmivora is severe. However, this is not the only disease of OP. BSR caused by Ganoderma boninense currently is a higher threat to the sustainability of OP in Malaysia and Indonesia, which is likely to increase with CC (Paterson et al. 2013; Paterson and Lima 2018, 2019; Paterson 2019a, b, 2020b) indicating that BSR would threaten the sustainability of the OP industry in Sumatra, Indonesia as a model for other OP growing regions in South East Asia. In addition, Paterson (2019b) indicated that BSR in Malaysia would be severe in the similar time frames discussed in the present paper. Other diseases also are present in Malaysian and Indonesian OP (Corley and Tinker 2015), some of which could be a greater threat in the future (Paterson et al. 2013). Hence, the sustainability of $\mathrm{OP}$ is challenged on many fronts. Farmers and the industry will be faced with low yields and poor growth of OP and they will have to contend with increasing disease incidence, leading to it becoming increasingly difficult to develop successful plantations.
(CT), 2030, 2070 and 2100 from Paterson et al. (2015) and CT, 2050 and 2100 from Paterson et al. (2017). The mortality of oil palm was assessed from the change in climate suitabilities particularly emphasizing the influence of marginal and unsuitable climates

Large negative changes to the climate and disease were reported in the current paper by 2050 but it is likely the detrimental changes will occur before that time. Consequently, there is little time to ameliorate the effect of these problems. In the case of $P$. palmivora, extremely effective quarantine procedures are required and current procedures should be revised. However, the causal organism of lethal bud rot may not be exclusively P. palmivora (Corley and Tinker 2015). It is essential that more work is undertaken to determine the contribution of $P$. palmivora and other organisms to the disease and to establish beyond doubt the factors that cause the disease. For example, whether the spear rot detected in Thailand is the same disease as bud rot requires investigation (see Introduction). Farmers and the industry in Malaysia and Indonesia require vigilance in inspecting their crop for any increased occurrence of diseases which are normally only present at low levels. Great care requires taking to avoid transfer of diseases between areas of low potential disease and high disease. This could be from regions within countries that have high incidence to areas with low incidence. Between country transfer needs avoiding such as between Indonesia, Malaysia and Thailand. Similarly the quarantine 
mechanisms must be enforced more strictly as CC progresses between (a) Africa and Latin America and (b) Malaysia and Indonesia.

The extent to which the data presented herein are accurate will emerge as time progresses. For example, it will be useful in 10,30, 50 years from now to assess to what extent the scenarios are correct, and this may provide confidence that the scenarios for 2100 . This applies if there were no attempts to prepare for $\mathrm{CC}$ effects on OP. If procedures to ameliorate the effects of CC were introduced then this would affect the parameters assessed in the current report. Nevertheless, methods are required urgently for ameliorating the effects of CC on OP (Paterson and Lima 2018). Government and policy officials will be able to use the present report to ensure that all precautions are taken to avoid the increase in OP mortality and diseases.

\section{Conclusions}

$\mathrm{OP}$ is under severe threat from $\mathrm{CC}$ in terms of the ability to grow new $\mathrm{OP}$ and survival of existing ones. It is likely that disease levels will increase from many pathogens and including $P$. palmivora. The palm oil industry will be threatened severely by the predicted changes in climate. Methods exist which may ameliorate the effects of $\mathrm{CC}$ on OP. Equally, it is incumbent on the OP industry to address the effect of growing $\mathrm{OP}$ on $\mathrm{CC}$.

Acknowledgements RRMP is grateful for the IOI Professorial Chair at Universiti Putra Malaysia he received for 2018-2019.

\section{Compliance with ethical standards}

Conflict of interest The author declares that has no conflict of interest.

\section{References}

Barcelos, E., Rios, Sd. eA., Cunha, R. N. V., Lopes, R., Motoike, S. Y., Babiychuk, E., et al. (2015). Oil palm natural diversity and the potential for yield improvement. Frontiers in Plant Science, 6, 1-16. https://doi.org/10.3389/fpls.2015.00190

Basiron, Y. (2007). Palm oil production through sustainable plantations. European Journal of Lipid Science and Technology, 109, 289-295. https://doi.org/10.1002/ejlt.200600223
Bellard, C., Bertelsmeier, C., Leadley, P., Thuiller, W., \& Courchamp, F. (2012). Impacts of climate change on the future of biodiversity. Ecology Letters, 15, 365-377. https://doi.org/10.1111/j.1461-0248.2011.01736.x

Brooke, C. (2008). Conservation and adaptation to climate change. Conservation Biology, 22, 1471-1476. https://doi. org/10.1111/j.1523-1739.2008.01031.x

Corley, R. H. V., \& Tinker, P. B. (2015). The Oil Palm. Chichester: Wiley Blackwell.

da Silva, R. S., Kumar, L., Shabani, F., \& Picanço, M. C. (2018). An analysis of sensitivity of CLIMEX parameters in mapping species potential distribution and the broad-scale changes observed with minor variations in parameters values: an investigation using open-field Solanum lycopersicum and Neoleucinodes elegantalis. Theoretical and Applied Climatology, 132, 135-144. https://doi.org/10.1007/s00704017-2072-2

Dislich, C., Keyel, A. C., Salecker, J., Kisel, Y., Meyer, K. M., Auliya, M., ... Wiegand, K. 2017. A review of the ecosystem functions in oil palm plantations, using forests as a reference system. Biological Reviews of the Cambridge Philosophical Society, 49, 1539-1569. Biological Reviews of the Cambridge Philosophical Society 49, 1539-1569.

Fitzherbert, E. B., Struebig, M. J., Morel, A., Danielsen, F., Brühl, C. A., Donald, P. F., \& Phalan, B. (2008). How will oil palm expansion affect biodiversity? Trends in Ecology \& Evolution, 23, 538-545. https://doi.org/10.1016/j. tree.2008.06.012

Ghini, R., Bettiol, W., \& Hamada, E. (2011). Diseases in tropical and plantation crops as affected by climate changes: current knowledge and perspectives. Plant Pathology, 60, 122-132. https://doi.org/10.1111/j.1365-3059.2010.02403.x

IPCC (2014). AR5 Synthesis Report - Climate Change 2014. Contribution of Working Groups I, II and III to the Fifth Assessment Report of the Intergovernmental Panel on Climate Change.

Kadandale, S., \& Smith, R. (2019). The palm oil industry and noncommunicable diseases Bull. World Health Organ, 97, 118-128.

Koh, L. P., \& Wilcove, D. S. (2008). Is oil palm agriculture really destroying tropical biodiversity? Conserv Lett, 1, 60-64.

Lamsal, P., Kumar, L., Shabani, F., \& Atreya, K. (2017). The greening of the Himalayas and Tibetan Plateau under climate change. Global and Planetary Change, 159, 77-92. https://doi.org/10.1016/j.gloplacha.2017.09.010

Lobell, D. B., Field, C. B., Cahill, K. N., \& Bonfils, C. (2006). Impacts of future climate change on California perennial crop yields: model projections with climate and crop uncertainties. Agricultural and Forest Meteorology, 141, 208-218. https://doi.org/10.1016/j.agrformet.2006.10.006

Mohamed Azni, I. N. A., Sundram, S., Ramachandran, V., \& Abu Seman, I. (2017). An in vitro investigation of Malaysian Phytophthora palmivora isolates and pathogenicity study on oil palm. Journal of Phytopathology, 165, 800-812. https://doi.org/10.1111/jph.12620

Murphy, D. J. (2014). The future of oil palm as a major global crop: opportunities and challenges. Journal of Oil Palm Research, 26, 1-24.

Ommelna, B. G., Jennifer, A. N., \& Chong, K. (2012). The potential of chitosan in suppressing Ganoderma boninense 
infection in oil-palm seedlings. Journal of Sustainable Science and Management, 7, 186-192.

Parmesan, C. (2006). Ecological and evolutionary responses to recent climate change. Annual Review of Ecology, Evolution, and Systematics, 37, 637-669. https://doi.org/10.1146 /annurev.ecolsys.37.091305.110100

Paterson, R. (2019a). Ganoderma boninense disease of oil palm is expected to significantly reduce production after 2050 in Sumatra if projected climate change occurs. Microorganisms, 7, 24.

Paterson, R. R. M. (2019b). Ganoderma boninense disease deduced from simulation modelling with large data sets of future Malaysian oil palm climate. Phytoparasitica, 47, 255-262. https://doi.org/10.1007/s12600-019-00723-4

Paterson, R. (2020a). Phytophthora present in oil palm? PLos $O n e . \mathrm{ht} \mathrm{t} p \mathrm{~s}: / / \mathrm{j}$ o u r n a $1 \mathrm{~s}$. p 1 o s. org/plosone/article/comment?id=10.1371 /annotation/afcb5949-27bc-4e37-a8b0-bf4525e986f2.

Paterson, R. R. M. (2020b). Oil palm survival under climate change in Kalimantan and alternative SE Asian palm oil countries with future basal stem rot assessments. Forest Pathology. In Press.

Paterson, R. R. M., \& Lima, N. (2018). Climate change affecting oil palm agronomy, and oil palm cultivation increasing climate change, require amelioration. Ecology and Evolution, 8, 452-461.

Paterson, R. R. M., \& Lima, N. (2019). Ecology and biotechnology of thermophilic fungi on crops under global warming. In: Tiquia-Arashiro SM (Ed.), Fungi in Extreme Environments: Ecological and Biotechnological Significance. Springer Verlag, pp. 81-96.

Paterson, R. R. M., Sariah, M., \& Lima, N. (2013). How will climate change affect oil palm fungal diseases? Crop Protection, 46, 113-120. https://doi.org/10.1016/j. cropro.2012.12.023

Paterson, R. R. M., Kumar, L., Taylor, S., \& Lima, N. (2015). Future climate effects on suitability for growth of oil palms in Malaysia and Indonesia. Scientific Reports 5. https://doi. org/10.1038/srep14457.

Paterson, R. R. M., Kumar, L., Shabani, F., \& Lima, N. (2017). World climate suitability projections to 2050 and 2100 for growing oil palm. Journal of Agricultural Science, 155, 689702. https://doi.org/10.1017/S0021859616000605

Ramirez-cabral, N. Y. Z., Kumar, L., \& Shabani, F. (2017). Global alterations in areas of suitability for maize production from climate change and using a mechanistic species distribution model (CLIMEX). Scientific Reports 1-13. https://doi. org/10.1038/s41598-017-05804-0.
Rosenzweig, C., Karoly, D., Vicarelli, M., Neofotis, P., Wu, Q., Casassa, G., et al. (2008). Attributing physical and biological impacts to anthropogenic climate change. Nature, 453, 353357. https://doi.org/10.1038/nature06937

Sarkar, S. K. (2020). Impacts of climate change on oil palm production in Malaysia. Environmental Science and Pollution Research. https://doi.org/10.1007/s11356-02007601-1.

Shabani, F., Kumar, L., \& Esmaeili, A. (2014). Future distributions of Fusarium oxysporum f. spp. in European, Middle Eastern and North African agricultural regions under climate change. Agriculture, Ecosystems and Environment, 197, 96105. https://doi.org/10.1016/j.agee.2014.08.005

Shabani, F., Cacho, O., \& Kumar, L. (2016). Effects of climate change on economic feasibility of future date palm production: An integrated assessment in Iran. Human and Ecological Risk Assessment, 22, 1268-1287. https://doi. org/10.1080/10807039.2016.1162089

Sinervo, B., Méndez-de-la-Cruz, F., Miles, D. B., Heulin, B., Bastiaans, E., Cruz, M. V. S., et al. (2010). Erosion of lizard diversity by climate change and altered thermal niches. Science, 328, 894-899. https://doi.org/10.1126 /science. 1184695

Sundram, S., \& Intan-Nur, A. M. A. (2017). South American Bud rot: A biosecurity threat to South East Asian oil palm. Crop Protection, 101, 58-67. https://doi.org/10.1016/j. cropro.2017.07.010

Thackeray, S. J., Sparks, T. H., Frederiksen, M., Burthe, S., Bacon, P. J., Bell, J. R., et al. (2010). Trophic level asynchrony in rates of phenological change for marine, freshwater and terrestrial environments. Global Change Biology, 16, 3304-3313. https://doi.org/10.1111/j.13652486.2010.02165.x

Urban, M. (2015). Accelerating extinction risk from climate change. Science, 348, 571-573.

Walsh, R. E., Aprígio Assis, A. P., Patton, J. L., Marroig, G., Dawson, T. E., \& Lacey, E. A. (2016). Morphological and dietary responses of chipmunks to a century of climate change. Global Change Biology, 22, 3233-3252. https://doi.org/10.1111/gcb.13216

Yonara, O., Costa, D. A., \& Tupinamba, D. D. (2018). Fungal diversity in oil palm leaves showing symptoms of Fatal Yellowing disease. PLos One 1-17.

Publisher's note Springer Nature remains neutral with regard to jurisdictional claims in published maps and institutional affiliations. 